\title{
А. К. ЧЕРЕДНИЧЕНКО
}

\section{Национальный университет кораблестроения имени адмирала Макарова, Украина}

\section{ПРИМЕНЕНИЕ ТЕРМОХИМИЧЕСКОЙ УТИЛИЗАЦИИ В ЭНЕРГЕТИЧЕСКИХ УСТАНОВКАХ ВЫСОКОТЕХНОЛОГИЧНЫХ СУДОВ}

\begin{abstract}
Статья посвящена вопросам применения термохимической утилизации в судовой энергетике. Проанализировано влияние роста мировой экономики на количественный и качественный состав мирового флота. Рассмотрены изменения, связанные с современными тенденциями развития судовой энергетики, требования, предвявляемые к судовым энергетическим установкам в среднесрочной перспективе, подходы к оценке актуальности применения новых энергосберегающих технологий. Учтень тенденции увеличения добычи ископаемых углеводородов с шельфа и необходимость формирования новых подходов к энергетике плавучих объектов нефтегазодобычи. Приведены результаты расчетов удельной стоимости на тонну дедвейта для разных типов судов. Установлено, что ряд судов (оффшорные суда, пассажирские суда, газовозы) могут быть выделены в группу высокотехнологичных судов. Выявлено, что термохимические технологии позволяют расиирить область применения альтернативных видов топлив и обеспечивают возможность использования разных типов тепловых двигателей в составе единых электрогенерируюших установок. Основной целью исследования является анализ применимости термохимической утилизации теплоты в энергетике высокотехнологичных судов. Методами математического моделирования проанализированы параметры газотурбинной установки для морской буровой платформы. Установка предусматривает паровую конверсию попутного газа путем утилизации теплоты отходящих газов ГТД. Выявлено, что наибольшей эффективностью обладает схема с двухступенчатым реактором паровой конверсии попутного газа. Расчет показателей эффективности термохимической конверсии показал полную конверсию тяжельх углеводородов. Полученные результаты совпадают с проведенными ранее исследованиями и подтверждают эффективность применения в энергетических установках высокотехнологических судов термохимической утилизации. Результаты исследований могут быть использованы при проектировании энергетических установок перспективных судов и плавучих объектов нефтегазодобычи.
\end{abstract}

Ключевые слова: судовая энергетическая установка; конверсия топлива; термохимическая утилизаичия теплоты; газотурбинный двигатель; синтез-газ.

\section{Введение}

Мировая экономика продолжает расти, что частично обусловлено глобальным ростом населения. Так по прогнозным данным BP Energy Outlook [1], к 2035 году мировое население увеличится до 8,7 миллиардов человек. Одновременно усиливается влияние на мировую экономику большого и растущего среднего класса в странах с развивающейся экономикой. Данные тенденции предусматривают повышение качества жизни, что в значительной мере связано с ростом объемов потребления материальных благ и энергетических затрат на единицу населения.

Освоение месторождений континентального шельфа создает основу обеспечения мировой экономики углеводородным сырьем на длительную перспективу. Это связано с выработкой к настоящему времени ресурса большинства доступных к разработке месторождений нефти и газа на суше. Свыше $37 \%$ объема мировой добычи нефти и $28 \%$ добы- чи газа приходиться на поля, расположенные на шельфе [2]. Главным образом это месторождения на Ближнем Востоке, Бразилии, Мексиканском заливе, в Северном и Каспийском морях, на Арктическом шельфе. Недавно открытые морские месторождения нефти и газа примерно в 10 раз превышают вновь открытые наземные месторождения.

Плавучие объекты нефтегазодобычи размещаются на значительных расстояниях от берега. Успешно применяются и разрабатываются различные технологии и технические средства для разнообразных условий окружающей среды. Все большее число объектов нефтегазодобычи относится к глубоководным и сверхглубоководным. Для обслуживания морских месторождений требуется многочисленный и разнообразный по составу оффшорный флот.

Рост объемов мировой экономики и, соответственно, рост мировой торговли приводит к увеличению объема транспортируемых грузов, главным образом морскими перевозками. По данным отчета 
UNCTAD свыше 70\% стоимости мировой торговли перевозится водным путем [3]. В 2017 г. общая масса перевезенного морем груза составила 10,7 млрд. тонн. По среднесрочным прогнозам на период 2018 ... 2023 гг. предполагается ежегодный рост объема перевозимого груза на 3,8 \% [4].

Мировой флот растет как по дедвейту, так и по количеству судов. На 1 января 2018 года количество судов мирового коммерческого флота составляло около 53 тысяч единиц [5]. Исследование характеристик объектов судоходства с использованием ключевых параметров эффективности [6] показывает, что многообразие функциональных задач, возлагаемых на морские суда и объекты океанотехники, формирует необходимость специализации судов. Это, в свою очередь, требует учета функционального назначения судна, особенностей его эксплуатации и других факторов при определении приоритетности внедрения инновационных технологий на этапе проектирования.

Одной из перспективных технологий повышения эффективности и экологичности применения судовых энергетических установок является утилизация вторичных энергоресурсов тепловых двигателей.

\section{1. Постановка задачи}

Представляет интерес оценка эффективности применения термохимической утилизации теплоты в энергетических установках перспективных судов.

\section{2. Изложение основного материала}

Повышение качества жизни связано не только с ростом уровня потребления материальных благ и повышением удельных энергетических затрат на единицу населения, но и с обеспечением качественных параметров окружающей среды.

Применительно к мировому флоту эта задача сводится к минимизации ущерба окружающей среде при одновременном повышении эффективности использования энергии топлива.

В нормативных документах Международной морской организации прямо указано, что применение инновационных технологий энергосбережения повышает энергоэффективность судна [7].

Стоимость судна дает представление о его сложности и технологичности [4]. Уровень коммерческой стоимости позволяет оценить масштабы инвестиций в применение перспективных техникоэкономических решений. При этом речь идет об инвестициях в технологии, которые судовладельцы должны вернуть за счет совершенствования мер по повышению эффективности, с целью покрытия переменных и постоянных издержек в процессе эксплуатации. Суда, созданные с применением инновационных технологий, могут быть отнесены к группе высокотехнологичных судов.

Анализ доли стоимости разных типов судов, в общей стоимости коммерческого флота (принята за $100 \%$ ) с учетом долей тоннажа и количества судов данного типа позволил выделить высокотехнологичные суда (рис. 1).

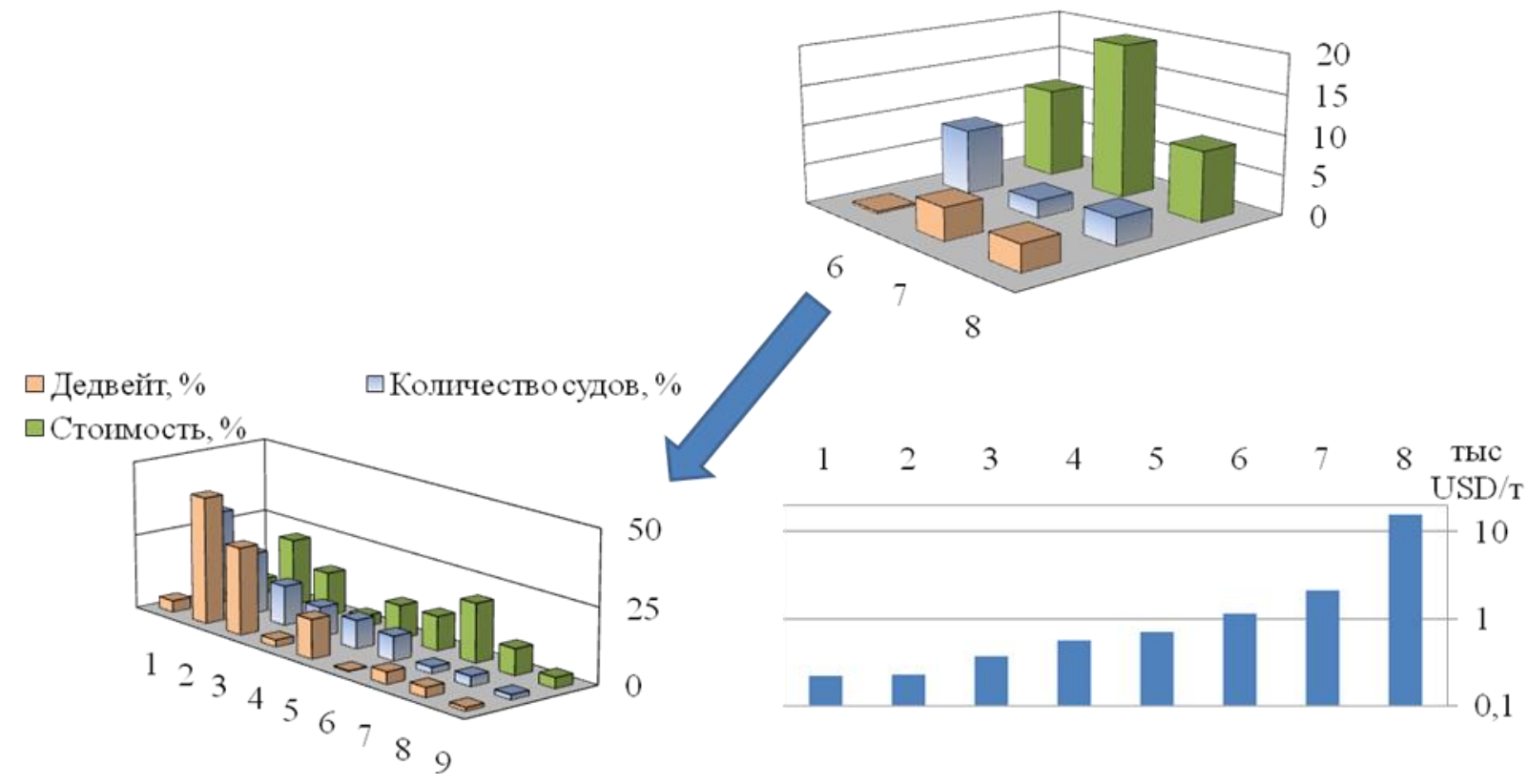

Рис. 1. Состав и характеристики мирового флота на 01.01.2018 [4]:

1 - универсальные суда; 2 - балкеры; 3 - нефтяные танкеры; ; 4 - танкеры-химовозы; 5 - контейнеровозы; 6 - пассажирские суда; 7 - оффшорные суда; 8 - газовозы; 9 - прочие 
Как видно из рис. 1, оффшорные суда (включая FPSO, FSRU, MODU, OSV и пр.), пассажирские суда (включая круизные лайнеры и паромы) и суда газовозы имеют удельную стоимость на тонну дедвейта, которая более чем в 2,5 раза превышает среднее значение. Стоимость таких судов составляет около $40 \%$ стоимости мирового флота, а дедвейт составляет не более $8 \%$.

Следует отметить, что выделение оффшорных судов, пассажирских судов и газовозов в группу высокотехнологичных судов, соответствует указанным в [8] сегментам судов, которые предпочтительны в качестве «испытательных полигонов» для отработки новых технологий.

Концепция применения термохимической утилизации вторичных энергоресурсов судовых двигателей соответствует основным тенденциям развития судовых энергетических установок, приведенным в аналитическом обзоре Global Marine Technology Trends 2030, подготовленном Lloyd's Register [8]. Согласно данному прогнозу, перспективными направлениями на ближайшие 15 лет будут:

- использование альтернативных видов топлива;

- применение дизель-электрических, комбинированных и гибридных установок,

- совершенствование технологий утилизации вторичных энергоресурсов.

Являясь технологиями утилизации вторичных энергоресурсов, термохимические технологии позволяют расширить область применения альтернативных видов топлива и обеспечивают возможность использования разных типов тепловых двигателей в составе единых электрогенерирующих установок.

Относительно первого направления, термохимические технологии предусматривают конверсию базового топлива с использованием тепловой энергии отработавших газов. В качестве базового энергоносителя могут использоваться такие альтернативные топлива как этанол/биоэтанол, метанол/биометанол, природный газ, попутный нефтяной газ разного состава, газообразное топливо на основе тяжелых углеводородов (этан, пропан, бутан и другие).

Второе направление соответствует тенденции применения термохимической утилизации в комбинированных дизель-газотурбинных электрогенерирующих установках. В таких установках предусматривается термохимическая утилизация теплоты отходящих газов ГТД путем паровой конверсии углеводородного топлива. Продукты конверсии используются в качестве топлива.

С целью проверки возможности применения термохимических технологий в судовой энергетике в предыдущих исследованиях были рассмотрены варианты энергетических установок с термохимической утилизацией вторичных энергоресурсов:

- установки на базе ГТД простого и регенеративного циклов $[9,10]$, в том числе с промежуточным теплоносителем [11];

- комбинированные дизель-газотурбинные установки [12, 13];

- дизельные установки на базе малооборотных двигателей с утилизационной металлогидридной установкой [14].

Данные транспортные и технологические энергокомплексы с термохимической утилизацией могут применяться на судах газовозах, паромах, круизных лайнерах, судах Ropax, морских буровых платформах и других плавучих объектах нефтегазодобычи.

В качестве иллюстрации возможности применения термохимической утилизации в судовой энергетике рассмотрена установка мощностью $10 \ldots 15$ МВт для морской буровой платформы. В качестве топлива принимается попутный нефтяной газ разного состава $[15,16]$. Использование такого топлива в ДВС проблематично из-за низкого метанового числа (MN). Ведущий производитель судовых ДВС фирма Wartsila не рекомендует к применению в своих двухтопливных двигателях топлива с метановым числом $\mathrm{MN}<46,8$. Для подготовки попутного газа к использованию в качестве топлива в ДВС Wartsila разработала установку GasReformer [17]. Установка предназначена для работы с СОД фирмы Wärtsilä мощностью 4...12 MW. Заявленный КПД составляет 44,5 \%.

Методами математического моделирования были проанализированы параметры альтернативной газотурбинной установки с паровой конверсией базового топлива путем утилизации теплоты отходящих газов. В качестве базовых параметров приняты характеристики ГТД Siemens SGT 400. Математическая модель установки создана на принципах, изложенных в работах $[10,12,13]$.

Моделирование проводилось при варьировании отношения пар/попутный газ при следующих ограничениях:

- фиксированная мощность ГТД (13,5 МВт);

- фиксированная температура газа перед турбиной $\left(\mathrm{T}_{3}=1500 \mathrm{~K}\right)$;

- параметры окружающей среды согласно ISO 19859:2016;

- температура газов за парогенератором принималась выше температуры точки росы, согласно рекомендациям [18].

В качестве критерия эффективности использования энергии топлива принят коэффициент полезного действия установки

$$
\eta=\left(\mathrm{Ne}-\sum \mathrm{N}_{\mathrm{add}}\right) /\left(\mathrm{C}_{\mathrm{N}} \cdot \mathrm{LCV}\right),
$$


где $\mathrm{Ne}$ - механическая мощность на выходном валу газотурбинного двигателя, кВт;

$\mathrm{N}_{\text {add }}$ - затраты мощности на привод насосов и компрессоров систем подачи топливного газа и термохимической утилизации, кВт;

$\mathrm{C}_{\mathrm{N}}$ - секундный расход топлива, кг/с;

LCV - низшая располагаемая теплотворная способность базового топлива, кДж/кг.

В качестве критерия оценки эффективности термохимической конверсии тяжелых углеводородов, содержащихся в попутном газе, была принята степень конверсии соответствующего углеводорода (этан, пропан, бутан, пентан).

Степень конверсии определялась как

$$
\xi=\left(\mathrm{q}_{\text {in }}-\mathrm{q}_{\text {out }}\right) / \mathrm{q}_{\text {in }},
$$

где $\mathrm{q}_{\text {in }}$ - мольная доля соответствующего углеводорода в попутном газе,

qout - мольная доля соответствующего углеводорода в топливном газе.

Упрощенная схема установки с двухступенчатым реактором риформером представлена на рис. 2 . Математическое моделирование процессов позволило сравнить эффективность разных схемных решений. Выявлено, что наибольшей эффективностью обладает схема с двухступенчатым реактором риформером паровой конверсии попутного газа.

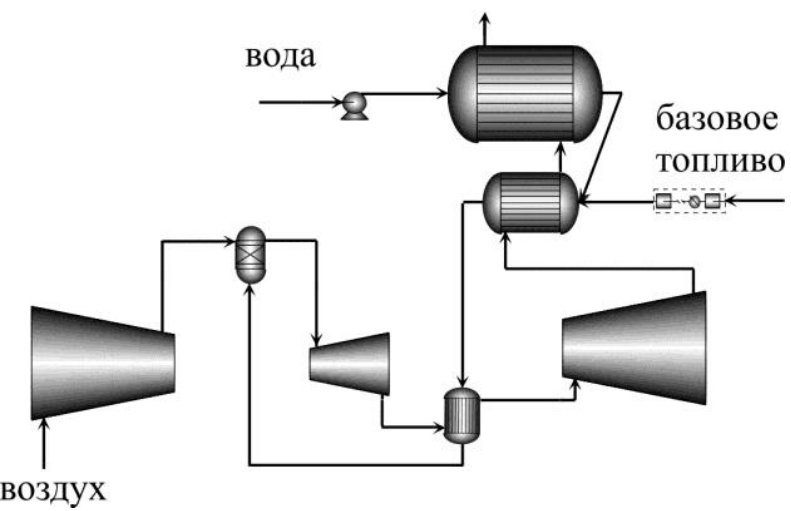

Рис. 2. Упрощенная схема газотурбинной установки с термохимической утилизацией

При базовых параметрах ГТД SGT 400 критерий эффективности использования энергии топлива лежит в диапазоне $46 \ldots 50 \%$ и зависит от состава конвертируемого попутного газа и допустимого отношения пар/попутный газ.

Расчет показателей эффективности термохимической конверсии показал полную конверсию тяжелых углеводородов (рис. 3).

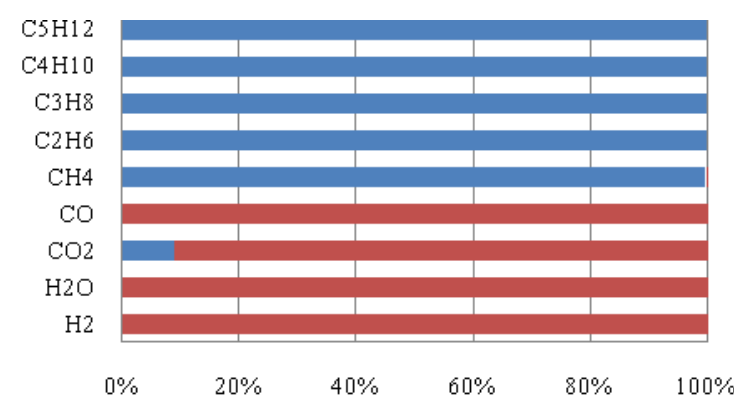

\begin{tabular}{|c|c|c|c|c|c|c|c|c|c|}
\cline { 2 - 10 } \multicolumn{1}{c|}{} & $\mathrm{H} 2$ & $\mathrm{H} 2 \mathrm{O}$ & $\mathrm{CO2}$ & $\mathrm{CO}$ & $\mathrm{CH} 4$ & $\mathrm{C} 2 \mathrm{H} 6$ & $\mathrm{C} 3 \mathrm{H} 8$ & $\mathrm{C} 4 \mathrm{H} 10$ & $\mathrm{C} 5 \mathrm{H} 12$ \\
\hline$-\Pi \Gamma$ & 0,00 & 0,00 & 0,01 & 0,00 & 0,68 & 0,15 & 0,09 & 0,05 & 0,01 \\
\hline $\mathbf{\mathrm { C } \Gamma}$ & 0,62 & 0,18 & 0,10 & 0,09 & 0,00 & 0,00 & 0,00 & 0,00 & 0,00
\end{tabular}

Рис. 3. Сопоставление состава (\%, моль) попутного газа (ПГ) и полученного в результате конверсии синтез-газа (СГ)

\section{Заключение}

Полученные результаты подтверждают результаты проведенных ранее исследований, согласно которым применение в энергетических установках высокотехнологических судов термохимической утилизации теплоты позволяет обеспечить необходимую энергетическую эффективность согласно перспективным требованиям Международной морской организации.

\section{Литература}

1. BP Energy Outlook: 2019 edition [Электронный ресурс]. - Режим доступа: https://www.bp.com/content/dam/bp/business-sites/en/ global/corporate/pdfs/energy-economics/energyoutlook/bp-energy-outlook-2019.pdf. -01.06.2019.

2. WOR 3 Marine Resources - Opportunities and Risks [Электронный pесурс]. - Режим доступа: https://worldoceanreview.com/en/wor-3/-01.06.2019.

3. UNCTAD/RMT/2017 [Электронный ресурс]. Режим docmyna: https://unctad.org/en /PublicationsLibrary/rmt2017_en.pdf.-01.06.2019.

4. UNCTAD/RMT/2018 [Электронный ресурс]. Режим доступа: https://unctad.org/en /PublicationsLibrary/rmt2018_en.pdf.-01.06.2019.

5. Number of ships in the world merchant fleet as of January 1, 2018, by type [Электронный ресурс]. Режим достуnа: https://www.statista.com/statistics 1264024/number-of-merchant-ships-worldwide-by-type. $-01.06 .2019$

6. Bazari, Z. Ship energy performance benchmarking/rating: methodology and application [Text] / Z. Bazari // Journal of Marine Engineering \& Technology. - 2007. - T. 6, № 1. - P. 11-18. DOI: 10.1080/20464177.2007.11020197. 
7. IMO Train the Trainer (TTT) Course on Energy Efficient Ship Operation. Module 2 - Ship Energy Efficiency Regulations and Related Guidelines [Электронный ресурс]. - Режим доступа: http://www.imo.org/ en/OurWork/Environment/PollutionPrevention/AirPollu tion/Documents/Air\%20pollution/M2\%20EE\%20regula tions\%20and\%20guidelines\%20final.pdf. - 01.06.2019.

8. Global Marine Technology Trends 2030 [Электронный ресурс]. - Режим доступа: https://eprints. soton.ac.uk/388628/1/GMTT2030.pdf. -01.06.2019.

9. Чередниченко, А. К. Показатели газотурбинной установки с термохимической регенераџией тепла [Текст] / A. К. Чередниченко, О. В. Ощчип // Intern. journal on operation of farm and agro-food industry machinery. - 2013. - Vol. 15, № 2. - P. 165 170 .

10. Чередниченко, А. К. Эффективность газотурбинной установки с термодинамической $u$ термохимической регенерацией тепла отходящчих газов [Текст] / А. К. Чередниченко, М. Р. Ткач // Авиационно-космическая техника и технология. - 2009. - № 7 (64). - C. 19-22.

11. Чередниченко, А. К. К выбору параметров промежуточного теплоносителя регенеративного газотурбинного двигателя [Текст] / A. К. Чередниченко, М. Р. Ткач // Вестник двигателестроения. - 2011. - № 2. - C. 101-105.

12. Cherednichenko, O. Analysis of Efficiency of the Ship Propulsion System with Thermochemical Recuperation of Waste Heat [Text] / O Cherednichenko, S. Serbin // J. Marine. Sci. Appl. - 2018. - № 1. - Vol. 17. - P. 122-130. DOI: 10.1007/s11804-018-0012-x.

13. Чередниченко, А. К. Моделирование энергокомплексов с термохимической регенерацией тепла для судов газовозов [Текст] / A. К. Чередниченко // Вестник двигателестроения. - 2016. - № 2. - C. 36-41. DOI: 10.20998/0419-8719.2017.1.09.

14. Чередниченко, А. К. Влияние климатических факторов на эффективность утилизационной металлогидридной установки двухтопливного малооборотного ДВС [Текст] / А. К. Чередниченко, М. Р. Ткач // Вісник НТУ «ХПІ». - 2017. - № 10(1232). - C. 85-91.

DOI: 10.20998/2078-774X.2017.10.12.

15. Farry, M. Ethane from associated gas still the most economical [Электронный ресурс]. - Режим docmyna: https://www.ogj.com/articles/print/ volume-96/issue-23/in-this-issue/gas-processing/ethanefrom-associated-gas-still-the-most-economical.html. 01.06.2019.

16. Modelling and analysis of offshore energy systems on North Sea oil and gas platforms. [Электронный ресурс] / T. Nguyen, B. Elmegaard, L. Pierobon at all // 53-rd International Conference of Scandinavian Simulation Society, SIMS 2012. - Режим достуna: https://www.researchgate.net/publication/263973093_ Modelling_and_analysis_of_offshore_energy_systems _on_North_Sea_oil_and_gas_platforms/figures?lo=1. -01.06 .2019 .
17. Wärtsilä GasReformer. [Электронный peсурс]. - Режим достуnа: https://www.offshoreeurope.co.uk/_novadocuments $/ 31687 ? v=63508966313$ 1000000. - 01.06.2019.

18. Kalinichenko, A. Heat Recovery Systems for Agricultural Vehicles: Utilization Ways and Their Efficiency [Tекст] / A. Kalinichenko, V. Havrysh, V. Hruban // Agriculture. - 2018. - № 8(12), 199. - P. 1-18. DOI: 10.3390/agriculture8120199.

\section{References}

1. BP Energy Outlook: 2019 edition. Available at: https://www.bp.com/content/dam/bp/business-sites/en/ global/corporate/pdfs/energy-economics/energyoutlook/bp-energy-outlook-2019.pdf.

(accessed 1.06.2019)

2. WOR 3 Marine Resources - Opportunities and Risks. Available at: https://worldoceanreview. com/en/wor-3/. (accessed 1.06.2019).

3. UNCTAD/RMT/2017. Available at: https:// unctad.org/en/PublicationsLibrary/rmt2017_en.pdf. (accessed 1.06.2019).

4 UNCTAD/RMT/2018. Available at: https:// unctad.org/en/PublicationsLibrary/rmt2018_en.pdf. (accessed 1.06.2019).

5. Number of ships in the world merchant fleet as of January 1, 2018, by type. Available at: https://www.statista.com/statistics/264024/number-ofmerchant-ships-worldwide-by-type. (accessed 1.06.2019).

6. Bazari, Z. Ship energy performance benchmarking/rating: methodology and application. Journal of Marine Engineering \& Technology, 2007, vol. 6, iss. 1, pp. 11-18. DOI: 10.1080/20464177.2007.11020197.

7. Train the Trainer (TTT) Course on Energy Efficient Ship Operation. Module 2 - Ship Energy Efficiency Regulations and Related Guidelines. 2016. Available at: http://www.imo.org/en/OurWork/Environment/ PollutionPrevention/AirPollution/Pages/IMO-Train-theTrainer-Course.aspx. (accessed 1.06.2019).

8. Global Marine Technology Trends 2030. Available at: https://eprints.soton.ac.uk/388628/1/ GMTT2030.pdf (accessed 01.06.2019).

9. Cherednichenko, O., Oschip, O. Pokazateli gazoturbinnoy ustanovki s termokhimicheskoy regeneratsiey tepla [Indicators of the gas turbine unit with the thermo-chemical heat regeneration]. Internal journal on operation of farm and agro-food industry machinery, 2013, vol. 15, iss. 2, pp. 165-170.

10. Cherednichenko, O., Tkach, M. Effektivnost gazoturbinnoy ustanovki $\mathrm{s}$ termodinamicheskoy i termokhimicheskoy regeneratsiey tepla otkhodyashchikh gazov [Efficiency of gas-turbine installation with thermodynamics and thermochemistry regeneration of warmth of exhaust gases]. Aviacijno-kosmicna tehnika $i$ tehnologia - Aerospace technic and technology, 2009, vol. 7 (64), pp. 19-22.

11. Cherednichenko, O., Tkach, M. K vyboru parametrov promezhutochnogo teplonositelya regenera- 
tivnogo gazoturbinnogo dvigatelya [To the choice of the parameters of intermediate heat -carrier of regenerative gas turbine engine]. Vestnik dvigatelestroenija - Herald of Aeroenginebuilding, 2011, vol. 2, pp. 101-105.

12. Cherednichenko, O., Serbin, S. Analysis of Efficiency of the Ship Propulsion System with Thermochemical Recuperation of Waste Heat. Journal of Marine Science and Application, 2018, vol. 17, iss. 1, pp. 122-130. DOI: 10.1007/s11804-018-0012-x.

13. Cherednichenko, A. Modelirovanie energokompleksov s termokhimicheskoi regeneratsiei tepla dlya sudov-gazovozov [Modeling of efficiency of ship power plants with ther-mochemical heat recovery for liquefied natural gas carriers]. Vestnik dvigatelestroenija - Herald of Aeroenginebuilding, 2016, vol. 2, pp. 36-41.

14. Cherednichenko, O., Tkach, M. Vliynie klimaticheskikh faktorov na efektivnost utilizatsionnoy metallogidridnoy ustanovki dvukhtoplivnogo malooborotnogo DVS gazovoza [Influence of Climatic Factors on the Efficiency of Disposal Metal-Hydride Unit for the Double-Fuel Low-Speed Internal Combustion Engine of Gas Tankers]. Trudy NTU "KhPI" - Bulletin of NTU "KhPI", 2017, vol. 10(1232), pp. 85-91. DOI: 10.20998/2078-774X.2017.10.12.
15. Farry, M. Ethane from associated gas still the most economical. Available at: https://www.ogj. com/articles/print/volume-96/issue-23/in-this-issue/gasprocessing/ethane-from-associated-gas-still-the-mosteconomical.html. (accessed 01.06.2019).

16. Nguyen, T., Elmegaard, B., Pierobon, L., Haglind, F., Breuhaus, P. Modeling and analysis of offshore energy systems on North Sea oil and gas platforms. 53-rd International Conference of Scandinavian Simulation Society, SIMS 2012. Available at: https://www.researchgate.net/publication/263973093_ Modelling_and_analysis_of_offshore_energy_systems _on_North_Sea_oil_and_gas_platforms/figures?lo $=1$. (accessed 01.06.2019).

17. Wärtsilä GasReformer. Available at: https:// www.offshore-europe.co.uk/_novadocuments/31687? $\mathrm{v}=635089663131000000$. $($ accessed 01.06.2019).

18. Kalinichenko, A., Havrysh,.V., Hruban, V. Heat Recovery Systems for Agricultural Vehicles: Utilization Ways and Their Efficiency. Agriculture, 2018, no. 8(12), 199, pp. 1-18.

DOI: $10.3390 /$ agriculture 8120199 .

Поступила в редакциию 03.07.2019, рассмотрена на редколлегии 7.08.2019

\section{ЗАСТОСУВАННЯ ТЕРМОХІМІЧНОЇ УТИЛІЗАЦІЇ В ЕНЕРГЕТИЧНИХ УСТАНОВКАХВИСОКОТЕХНОЛОГІЧНИХ СУДЕН}

\section{О. К. Чередниченко}

Статтю присвячено питанням застосування термохімічної утилізації в судновій енергетиці. Проаналізовано вплив зростання світової економіки на кількісний і якісний склад світового флоту. Розглянуто зміни, пов'язані з сучасними тенденціями розвитку суднової енергетики, вимоги, що пред'являються до суднових енергетичних установок в середньостроковій перспективі, підходи до оцінки актуальності застосування нових енергозберігаючих технологій. Враховано тенденції збільшення видобутку вуглеводнів 3 шельфу та необхідність формування нових підходів до енергетики плавучих об'єктів нафтогазовидобутку. Наведено результати розрахунків питомої вартості на тонну дедвейту для різних типів суден. Встановлено, що ряд суден (офшорні судна, пасажирські судна, газовози) можуть бути виділені в групу високотехнологічних суден. Виявлено, що термохімічні технології дозволяють розширити сферу застосування альтернативних видів палива та забезпечують можливість використання різних типів теплових двигунів у складі єдиних електрогенеруючих установок. Основною метою дослідження $є$ аналіз застосовності термохімічної утилізації теплоти в енергетиці високотехнологічних суден. Методами математичного моделювання проаналізовані параметри газотурбінної установки для морської бурової платформи. Установка передбачає парову конверсію попутного газу шляхом утилізації теплоти відхідних газів ГТД. Виявлено, що найбільшої ефективністі відповідає схема 3 двоступінчастим реактором парової конверсії попутного газу. Розрахунок показників ефективності термохімічної конверсії показав повну конверсію важких вуглеводнів. Отримані результати збігаються з проведеними раніше дослідженнями та підтверджують ефективність застосування в енергетичних установках високотехнологічних суден термохімічної утилізації. Результати досліджень можуть бути використані при проектуванні енергетичних установок перспективних суден та плавучих об'єктів нафтогазовидобутку.

Ключові слова: суднова енергетична установка; конверсія палива; термохімічна утилізація теплоти; газотурбінний двигун; синтез-газ.

\section{APPLICATION OF THERMOCHEMICAL WASTE HEAT RECOVERY IN POWER PLANTS OF HIGH-TECH SHIPS \\ o. Cherednichenko}

The research's subject is the processes of energy transformation of fuel in the ship power plant with thermochemical waste heat recovery. Modern approaches to assessing the energy efficiency of ship power plants were 
considered. The characteristics of traditional and perspective ships were analyzed. Passenger ships (including Ro-Ro ferry and cruise ships), offshore ships (including FPSO, FSRU, MODU, OSV, etc) and LNG/LPG carriers are classified as high-tech ships. It is discussed the application of thermo-chemical waste heat recovery in power plants of high-tech ships. It is proposed to increase the efficiency of fuel use by using synthesis gas obtained through thermochemical heat recovery of secondary energy resources of ship engines. The main objective of the study is to analyze the energy efficiency of steam thermo-chemical transformation of fuel in ship power plants. It is presented the design scheme of the marine power plant for an offshore platform. It is shown the mathematical model of the ship gas turbine installation with thermo-chemical heat recovery by steam conversion of associated gas. The associated gas conversion efficiency was determined by the heat potential of the exhaust gases and was calculated based on the thermal balance of the thermochemical reactor. The reactor has two stages. It is presented the results of mathematical modeling of processes in plant-based on gas turbine engine of the simple cycle under conditions of fixed output power, the fixed temperature of the gas in the turbine's front for environmental parameters according to ISO 19859: 2016. It is revealed the efficiency of the scheme which used steam conversion of associated gas in the two-stages reactor. Calculation of thermo-chemical conversion efficiency indicators showed the complete conversion of heavy hydrocarbons. The increase in the energy efficiency of the installation is $10 \ldots 12 \%$. The results obtained coincide with previous studies and confirm the effectiveness of the use of thermo-chemical heat recovery in power plants of high-tech ships. The research results can be used in the promising marine power plants designing.

Keywords: ship power plant; fuel conversion; thermo-chemical recuperation; gas turbine engine; syngas.

Чередниченко Александр Константинович - канд. техн. наук, доцент кафедры судовых и стационарных энергетических установок Национального университета кораблестроения им. адмирала Макарова, Николаев, Украина.

Cherednichenko Oleksandr Constantinovich - Candidate of Technical Science, Assistant Professor of Dept. of ship and stationary power plants, Admiral Makarov National University of Shipbuilding, Ukraine,

e-mail: oleksandr.cherednichenko@ nuos.edu.ua, ORCID Author ID: 0000-0001-8746-9132,

ResearcherID K-3554-2018, https://scholar.google.com.ua/citations?user=XNrAwwUAAAAJ\&hl=en 